Porpoise), three inches long (as if extended), lent to Prof. Wilder by Mr. Alex. Agassiz, Curator of the Museum of Comp. Zoology at Cambridge. The last two specimens are believed to be the smallest of their kind hitherto recorded.

Prof. Wm. S. Barnard, of Canton, IIl, read a paper On the Development of the Opossum, Didelphys virginiana.-Prof. Barnard read another paper, in which he compared the muscles of man with those of the higher apes, showing the points of similarity as well as of difference. An interesting point made in this paper was the statement that one of the buttock muscles supposed to be peculiar to the higher apes, distinguishing them from man, really existed in the human body and in a similar position. It was shown that the muscle thus described by Traill, and afterwards by Wilder as in the chimpanzee, and by Owen and Bischoff as in the orang, and by Coues as in the opossum, is also found in man, and offers no distinction in this respect. Three new muscles about the hip-joint, found in the orang and some other apes, were also made the subject of description; these muscles have no homologues in man. Two of these act to rotate the leg and draw it inward; the other seems too small to have any functional value and is probably a rudiment, but is interesting as occurring also in some of the lower apes and the opossum. The other muscles in this region of the body were like those of man, but in the case of an orang the short head of the biceps of the thigh was found entirely separated. This is only occasionally the case with the orang, and this peculiarity is not known to exist in any other animal. The two large external muscles of the calf do not unite with each other to form a single tendon Achillis, consequently in the orang this tendon is double, which sometimes occurs with marsupials. These investigations, which were explained in much technical detail, tend to prove that all the muscles possessed by man can be traced backward in the lower forms of animals, through the apes to the lemuroids.

Prof. Barnard gave a detailed account of his observations on the Protozoa, made in the anatomical laboratory of Cornell University, Ithaca, N. Y., where the specimens described were also seen by Prof. Wilder and others than the investigator himself.

Prof. George F. Barker, of Philadelphia, read a paper On the Cause of the Relative Intensity of the Broken Lines of Metallic Spectra. The purpose of this paper is to give the general result of a series of measurements made to ascertain, by Vierordt's method, the relative intensity of these various lines, and to compare these with their lengths measured micrometrically. Vierordt's method consists in measuring the intensity of a coloured light by the amount of white light necessary to extinguish it. By means of a third telescope attached to the spectroscope, a bright slit of light may be thrown upon any portion of the spectrum, and by varying the distance of the source of this light, until it extinguished the various spectrum lines in the order of their brightness, a series of numbers was obtained which, by the law of the inverse squares, gave the relative intensity of the different spectrum lines. The metals experimented upon were copper, gold, silver, antimony, bismuth, and magnesium. The general result is, that in no case does the length of the spectrum line follow the law of brightness. Hence some other hypothesis must be suggested to account for the phenomena. The author suggested one which seemed to him to be at least possible, and to be sustained by the prevalent views on molecular and atomic physics. The constitution of a gas is simple; the molecules composing it move in straight lines, and encounter each other and the walls of the containing vessel in so complex a way that Prof. Max. well doubts if mathematics can follow their paths. The oscillations of the atoms within the molecule, are, however, less complex; they either are simple harmonic motions themselves, or they may be resolved into such. It is these harmonic vibrations which, communicated to the ether, cause the spectrum lines; the number of the different forms of oscillation constituting the number of lines in the spectrum, the period of any one oscillation determining the wave length of the corresponding line, and the amplitude fixing the brilliancy of that line. These things being granted, we have only to suppose what is perfectly conceivable, that the amplitude of the vibration, the only point we are now concerned with, varies with the temperature difierently for each of the different kinds of vibration in the molecule, or, what is the same thing, with the wave length. If, for example, the peculiar harmonic vibration of the atoms of a copper molecule which gave the longest line in the green, diminished the amplitude of its oscillation less rapidly than the one in the blue, then this is a sufficient reason why it should be the longest. We may, therefore, by inspection of a broken spectrum, conclude at once on the rapidity with which the amplitude of the different harmonic vibrations of the atoms within the molecule decreases with decreasing temperatures, this being simply in the order in which the lines are arranged as to their length. This is offered as a working hypothesis to be proved or disproved by special investigation. From the facts already known it may be regarded as antecedently probable. It seems to be a step taken into the great field lying between chemistry and physics, at present a great and unexplored gulf. Work done here cannot be thrown away even if done to test an untenable hypothesis. It must bear fruit, though it may, be very different in kind from that anticipated.

\section{REPORT ON THE PROGRESS AND CONDI- TION OF THE ROYAL GARDENS AT KEW DURING THE YEAR 1874}

FROM Dr. Hooker's recently issued report on the progress and condition of the Royal Gardens, Kew, for 1874, we learn that a series of lectures, or, as they are called in the report, "practical lessons," have been given to the gardeners during the evenings, after worling hours. These "lessons" embrace the elements of structural, systematic, and physiological botany; of chemistry, physical geography, and meteorology, in their application to horticulture ; of economic botany, forestry, \&c. They are given, some in the young men's Library, others in the Garden or Museum. Notes of these lessons have to be taken by those attending them, which, after being fairly written out in notebooks, are examined periodically by the teacher and corrected, or more explicit instruction given if necessary. The attendance at these lessons is voluntary, but the fact of "good altendance" is recorded in every gardener's certificate of conduct and proficiency on his leaving the service of the establishment.

These lessons have been instituted with the view of the better education of the gardeners in subjects bearing upon their profession, so as to qualify them for "Government and other situations in the Colonies and India, where a scientific knowledge of gardening, arboriculture, \&c-, is required." Mast of the colonial gardens and Government plantations are at the present time under the superintendence of able men, who received at some time or another instruction at Kew.

The liability of Coffea arabica to the attack of both insects and fungi have been abundantly proved of late by the visitation of the so-called blights in Dominica, Southern India, and more recently in Ceyion. In consequence of this a good deal of interest is attached to the prosperity of the Liberian Coffee, which has been distributed from Kew. On this subject Dr. Hooker says : "A large stock of true Liberian Coffee has been obtained through the kind efforts of Messrs. Irvine and Woodward, of Liverpool. This is a larger and perhaps differen t variety from that received from Cape Coast. . . . Large quantities of both have been sent to the coffee-growing British possessions, and have arrived in excellent condition. Dr. Thwaites states that the Cape Coast Coffee, the safe arrival of which in Ceylon I mentioned in the report of last year, is, notwithstanding that it was immediately attacked by the leaf disease, doing well. $\mathrm{He}$ also remarks that 'the Cape Coast and Liberian Coffees, although they would seem to differ much as regards size of their respective seeds, yet in the matter of foliage there is great resembiance between them. In this latter respect they differ considerably from the ordinary coffee plant of Ceylon, their leaves being a good deal larger, more firm in texture, and tapering more gradually to the base."

The increased cultivation of coffee, and the introduction of varieties better suited to resist the altacks of disease, has, it appears, attracted the attention not only of the British Government, but also of the Colonial Governments, so that a good deal of correspondence has arisen with Kew on the subject. Dr. Hooker says: "My attention has in consequence been directed (I) to obtaining accurate reports as to the nature of the disease, of which several are confounded under one common epithet; (2) to recommending measures for the cultivation of coffee in colonies once famous for its production where it has been almost abandoned, as well as in others where the cultivation has been scarcely attempted; and (3) to the cultivation of new and improved varieties."

The Blue Gum Tree (Eucalyplus globuluss), which has now become so popular that plants some twelve or fourteen feet high may be seen growing in the open air in some of our London parks, is recommended for planting by Dr. Hooker, simply on 
account of its quick growth and its value as a timber tree, the wood being exceedingly hard and durable. With regard to its supposed beneficial effects in malarious districts, Dr. Hooker says he is "still unable to endorse the views of those who regard the tree as capable of cultivation in tropical swamps and as a prophylactic against ague and fever."

The prospects of the Ipecacuanha cultivation in India is, we are told, not very encouraging, owing rather to the slow growth and small yield of the underground root stock from which the drug is obtained, than to the want of success in growing and propagating the plants. "Nevertheless the cultivation must be persevered in. The causes that retard the progress of this valuable herb under cultivation are those that raise the price of it in its native country. Were it a plant that increased rapidly, it would be with difficulty eradicated from the forests which it inhabits."

One very important matter mentioned in the report is that referring to the new Herbarium, the site for which is not yet, however, determined upon. It is, moreover, satisfactory to learn that when erected it will, through the liberality of Thomas Philip Jodrell, Esq., M.A., the founder of the Jodrell Professorship (of Physiology) in University College, London, be associated with a laboratory for physiological botany. The contributions to the Gardens of living plants and seeds, to the Herbarium of dried plants, and to the museums of economic specimens, have been exceedingly numerous and interesting.

\section{NOTES}

M. JANSSEN'S appointment as the head of a new French Physical Observatory, which we intimated some tine ago, has been gazetted. The French Government, we believe, wishes

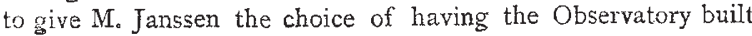
at Fontenay, as was originally decided upon, or at Vincennes, which is at a less distance from Paris.

Mr. Watson, at Monday's sitting of the French Academy, read a long and interesting paper on the observations of the Transit of Venus made at Peking station, of which he was the chief. The question of the atmosphere of Venus and the difficulty of determining the exact time of real contact were examined at full length. M. Leverrier expressed his decided opinion that the determination of the parallax of the sun by this method was useless unless some unexpected service should be rendered by photography for solving the difficulty raised by Mr. Watson. Mr. Watson tried to discover to what height the atmosphere of Venus was liable to cause optical disturbances by its illumination by the sun, and he found it to be fifty-five miles, about x-yoth the diameter of the planet.

THE Kirtland Summer School of Natural History (named in honour of Dr. Jared P. Kirtland) was inaugurated July 6, 1875, in Cleveland, Ohio (U.S.) The session this year extended through five weeks, closing August 9, with appropriate exercises. The school was founded on behalf of the Kirtland Society of Natural Sciences, by Prof. Theo. B. Comstock and Dr. Wm. K. Brooks. Instruction was given in botany and entomology by Prof. Theo. B. Comstock, of Cleveland; in general invertebrate zoology by Dr. Wm. K. Brooks, of Cambridge, Mass, ; in microscopy and protozon by Prof. Albert H. Tuttle, of the Ohio Agricultural and Mechanical College, Columbus, Ohio ; and a short course of lectures on geology was given by Dr. J. S. New. berry, of Columbia College, New York City, Director of the Ohio Geological Survey. The work was all done in the laboratory and in the field, text-books being wholly discarded. Twentyfive enthusiastic pupils, many of them lady teachers, availed themselves of the advantages afforded for the small fee of ten dollars. The expenses were paid by a subscription fund, the instructors receiving but slight compensation by a division of the small balance in hand. The session was yery profitable, and it is hoped that the school will be continued year after year.

THE French Department of the International Maritime Exhibition contains a large number of apparatus intended for the raising of wrecks from the bottom of the sea. Working models of these have been sent in by M. Bazin, an engineer. This inventor has organised an immense submarine observatory which enables the bottom of the sea to be inspected with perfect security. M. Roselli, an Italian engineer, exhibited a selfmoving gigantic grapnel, which being worked by steam could render great 'service to raise even such heavy weights as the Vangzard. M. Bazin has also invented a ship for dredging at small depths when it is necessary to open a channel for a port. Several ships of this kind have been constructed for the Russian Government, and are now at work in Russian waters. The principle involves the use of syphons, which are let down to the bottom and are so worked as to send mud, sand, and water into the main hold of the vessel, from which they are taken out by powerful steam-engines.

A UNIVERSTTY is to be founded at Tomsk, one of the chief towns of Siberia. The new establishment will have only two faculties, one of Law and the other of Medicine. The want of doctors in Siberia may be inferred from the fact that there are only fifty-five of them in a country which is as large as the whole of Europe, and whose population amounts to more than 6,000,000 inhabitants. The Russian Minister of Finance has granted a credit of $40,000 \%$. On the revenue of the State for the new establishment, which will raise the number of Russian Universities to eight, seven others being already in existence, viz., St. Petersburg, Moscow, Kiew, Kazan, Kharkow, Odessa, Varsovie, besides two foreign Universities-a German one in Dorpat, and a Swedish one in Helsingfors. A new University is also to be established in Vilna.

Captain Waterhouse writes that he has verified $\mathrm{Dr}$. Vogel's discovery of the influence of certain dyes in increasing the sensitiveness of bromide of silver to the less refrangible rays of the spectrum.

AN examination will begin at Merton College on Tuesday, October 12, for the purpose of electing to one Mathematical and one Physical Science Postmastership. The postmasterships are of the annual value of $80 \mathrm{l}$., and are tenable for five years trom election, or so long as the holder does not accept any appointment incompatible with the pursuance of the full course of University studies. After two years of residence the College will raise by a sum not exceeding $20 \%$. per annum the postmasterships of such postmasters as shall be recommended by the tutors for their character, industry, and ability. Further information may be obtained from the Mathematical and Physical Science Tutors.

Mr. E. J. MiLLS, D.Sc., F.R.S., has been appointed Young Professor of Technical Chemistry in Anderson's College, Glasgow, on the resignation of Prof. Gustay Bischof.

WE would direct the attention of zoologists to a sketch and description by Prof. Wilder, of Cornell University, in the American Fournal of Science and Art for last month, of a foetal Manatee whose total length is 3.7 inches. "The head (which is somewhat pig-like) is strongly flexed upon the chest, and the tail forms a right angle with the trunk; " a contour very different from the adult animal being the result. The specimen was obtained at Pebos, Peru, upon the Marañon, a tributary of the Amazons, by Prof. James Orton.

In a letter to yesterday's 7 imes, $\mathrm{Mr}$. W. L. Watts gives a long description of a volcanic eruption which he witnessed last month on the Myvatns Oroef, in Iceland.

THE Berlin Geographical Society has receiveda telegram from Lisbon, dated the rith inst., announcing that Dr. Pogge and Lieut. Xux, with their African Exploring Expedition, were on their way from Cassandje to Lunda. Major von Homeyer was still on the coast. 